\title{
Performance Analysis of Conventional, Quadratic and Double Cascaded Boost Converters in a PV System with $P$ and $O$ based MPPT Controller
}

\author{
Servavidya Kumar Manas \\ Department of Electrical Engineering \\ Delhi Technological University
}

\author{
Bharat Bhushan \\ Department of Electrical Engineering \\ Delhi Technological University
}

\begin{abstract}
In this paper, performance analysis of three different DC/DC converter topologies i.e. a conventional, a quadratic and a double cascaded boost converter for a Solar PV system, driven by Perturb and Observe based MPPT controller is proposed. A boost topology is used to increase the output voltage of a solar PV module. However, for the case where high step-up ratio is required, a conventional boost converter may not fulfill the purpose and therefore cascaded boost converters are employed to overcome this limitation. Cascaded boost converters provide high voltage conversion ratio along with higher efficiency values, in comparison to conventional boost converter. Perturb-and-observe (P\&O) technique is a very widely used technique for operating the solar PV system at maximum power point, because of its simple structure, simplicity of algorithm and its low-cost implementation in a microcontroller based real systems. This MPPT algorithm extracts the maximum power point from the PV panel module corresponding to a constant load resistance under various pairs of solar radiation and ambient temperature. For all the three converter topologies. MATLAB/ Simulink software is used to simulate the circuits. The results are compared to evaluate the overall performance of the Solar PV system in each case.
\end{abstract}

\section{Keywords}

Solar Photovoltaic System, DC-DC Converter, Conventional Boost Converter (CBC), Quadratic Boost Converter (QBC), Double Cascaded Boost Converter (DCBC), MPPT, MATLAB and SIMULINK.

\section{INTRODUCTION}

Among all renewable energy sources like wind, solar, geothermal, tidal, biomass, and hydropower, solar photovoltaic (PV) system represents a very important and reliable energy source as it provides very clean energy without any environmental effect. Design of solar PV system is presented in [1] and [2], whereas a complete overview of PV system is discussed in [3]. In paper [4] design consideration of standalone PV system is presented while [5] discusses design and implementation of on-grid solar system. A standalone system with MPPT control is proposed in [6].

A solar PV system with dc-dc converter and MPPT controller is shown in Figure 1. The system performance in renewable energy sources is improved using DC-DC converters, which are the key part in a photovoltaic chain. Boost converter is the most used DC-DC topologies because of its simplicity and high efficiency. However, traditional boost converter cannot meet the demand, if higher voltage step-up ratio is required by the solar PV system. The solar PV modules are having limitations of having relatively, low-efficiency levels compared to the efficiency of conventional fossil fuel and other renewable energy sources such as wind or hydro. The energy conversion efficiency of PV modules is very low, in contrast to high in price. Thus, it is indispensable that a photovoltaic system must operate at its maximum output power levels in all operating conditions of temperature and solar irradiation level at all the time. The output voltage, current and power of a solar photovoltaic system vary as functions of solar irradiation level and temperature for a given load. Therefore, the operating point of the photovoltaic panel $\mathrm{PV}$ does not always operate at the maximum power point.

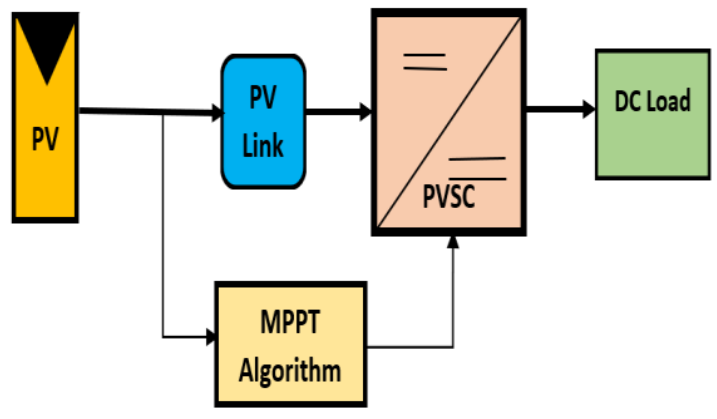

Figure 1: Block diagram of a Solar PV System

A possible solution to the problem of obtaining higher voltage step-up ratio is to use other boost converter topologies like cascaded boost converter configurations. Several research works are done on various converters for obtaining high stepup voltage. A cascaded high step-up dc-dc converter with the coupled inductor with lossless passive snubber is proposed in [6]. A new high step-up cascaded DC-DC converter is proposed in [7], whereas in [8] novel high step-up DC/DC converter consists of a coupled inductor and two voltage multiplier cells in order to obtain high step-up voltage gain is presented. In [9] a new high step-up dc-dc converter is proposed which has two switches that operate in two operational modes. In [10] the researchers dealt with the ripple cancellation in a dc-dc converter. In [11] authors design and compare a conventional and a quadratic boost converter. The issue of operating the Solar PV Module at the maximum power point at all operating conditions is resolved by applying maximum power point tracking techniques. In [12] quadratic boost converter is derived from the generalized cascaded boost topologies with a single switch and the double cascade boost emerges from the association of two identical elementary boost converters connected in tandem. Here the researchers present a comparison of the efficiency of the $\mathrm{CBC}$ with cascaded boost converters and finds that the double cascade boost has the best response as the result of its ability to boost up the voltage even with a low input value. Also, it 
was concluded that the operation with a single active switch in QBC to be very attractive in spite of its efficiency slightly lower than DCBC.

There are available great numbers of MPPT techniques in today's market to maintain the operation of PV module at maximum power. In different literatures, the maximum power point (MPP) is called as the "peak power point" (PPP) or "optimal operating point" (OOP). PV systems are expected to operate at their maximum output power levels in all operating conditions i.e. for various temperature and solar irradiation level. The output voltage, current and power of a solar photovoltaic system vary as functions of solar irradiation level and temperature for a given load. Therefore, the operating point of the photovoltaic panel PV does not always coincide with the maximum power point. To overcome the adverse effects of the variable temperature and solar irradiation on the output power of PV systems, two different control strategies have usually been applied: (a) controlling the solar power input to the PV array (b) controlling the electrical power output from the PV array. The solar-tracking method is used to maximize the solar power input and is a mechanical tracking - where the solar panels are on a mount that follows the sun. A maximum power point tracking (MPPT) is a control algorithm used to extract maximum electrical power output possible from the PV module and is an electrical tracking. Electrical MPPT techniques are classified into three families as, off-line techniques, on-line techniques and artificial intelligence techniques. Fractional open-circuit voltage (FOCV) and fractional short-circuit current (FSCC) techniques comes under; such as perturb-and-observe (P\&O) and incremental conductance (InCond) techniques; , (AI) techniques including fuzzy logic control (FLC) technique, artificial neural network (ANN) technique, particle swarm optimization (PSO) technique, genetic algorithm (GA) and Grey-Wolf Optimization (GWO). Several studies have focused on and tried to develop algorithms to extract the maximum energy converted by the panel. In [13], [14] a comparative analysis of various MPPT methods are presented. In [15] a review is presented for widely used MPPT control techniques in solar PV system. In [16] a comprehensive study to deal with the maximum power tracking of the Photovoltaic Energy System (PVES) using both classical and modern MPPT techniques are compiled.

In this paper performance of $\mathrm{CBC}, \mathrm{QBC}$ and $\mathrm{DCBC}$ is analyzed for a solar PV system using P\&O MPPT based controller. In section 2, circuit analysis of dc-dc converters is presented. In section 3, various MPPT techniques are discussed and $\mathrm{P} \& \mathrm{O}$ method is briefly described. Simulations and results are presented in section 4 and conclusions in section 5 .

\section{DC-DC CONVERTERS}

Power electronic systems are essential for harnessing renewable energy such as wind energy, solar energy using photovoltaics etc. Converter design is a major research area in the field of power electronics. Harnessing of solar energy using photovoltaics, requires $\mathrm{dc}-\mathrm{dc}$ converters to convert voltages and currents from one dc level to another, and to operate these systems optimally. Besides this, dc-dc converters function also as the fundamental block of conversion between ac and dc voltages, required in applications such as harnessing of wind energy etc. There are several topologies commonly used to implement DC-DC converters, like Buck, Boost and Buck-Boost converters. Each converter's topology has its own unique features, which makes it best suited for a certain application. A boost topology is selected when output voltage needs to be higher than photovoltaic side voltage. Conventional boost converter is the most used boost converter because of its simplicity and high efficiency. However, it is pertinent to mention that a conventional boost converter cannot meet the demand of high step-up ratio requirement of the system. Thus, the need to have converters having higher voltage conversion ratio with no compromise in performance, brings DC-DC cascaded converters as an optimal solution

\subsection{The Conventional Boost Converter}

A quadratic boost converter is shown in Figure 2.

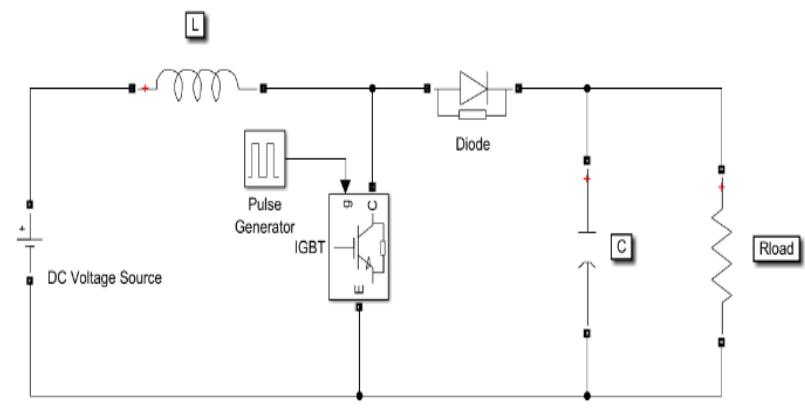

Figure 2: A Conventional boost converter

A conventional boost converter basically comprises one capacitor, one inductor, one passive switch (i.e. diode) and one active switch (IGBT). The boost converter has two possible modes of operation in continuous mode.

Mode 1: On-State

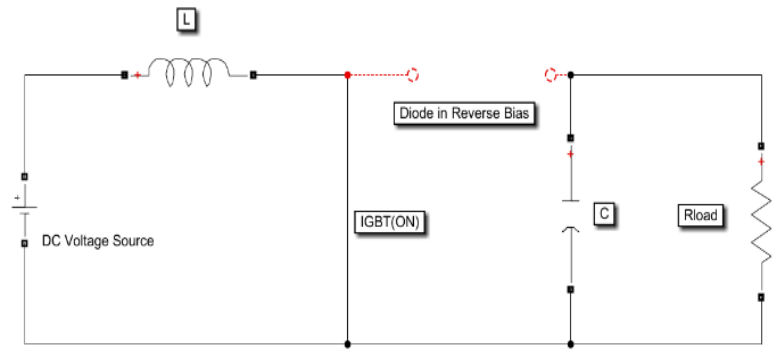

Figure 3: A conventional boost converter (On-State)

The mode 1 circuit of conventional boost converter is given in Figure 3. In on-state, active switch (IGBT) is turned on, whereas the diode, $\mathrm{D}$ is reverse biased. The inductor, $\mathrm{L}$ gets charged via the supply voltage from the capacitor, $\mathrm{C}$ and stores the energy. During this state, the inductor, L current increases gradually.

Mode 2: Off-State

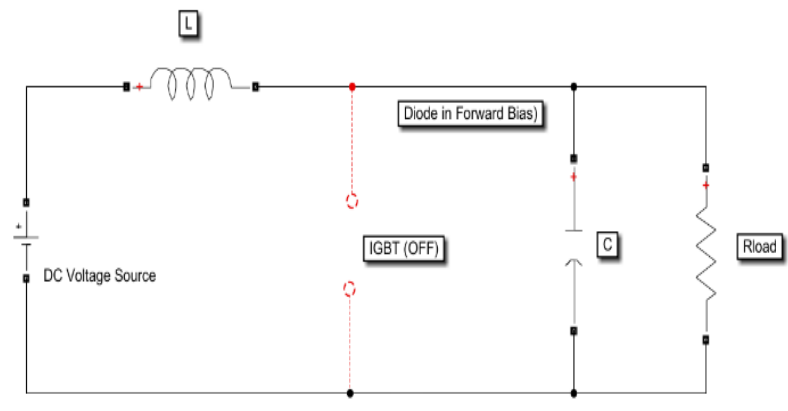

Figure 4: A conventional boost converter (Off-State) 
The mode 2 circuit of conventional boost converter is given in Figure 4. In off-state, switch (IGBT) is turned off. The energy stored in the inductor; L changes its polarity to charge the capacitor, $\mathrm{C}$ through the diode.

A high value capacitor Cin, act as DC-Link. Let Vin is the input voltage, Vout is the output voltage, $\Delta i_{L}$ the ripple current, $\Delta v_{c}$ the ripple voltage and $f$ be the switching frequency. Then,

The duty cycle is given by

$$
D=1-\frac{v_{\text {in }}}{v_{\text {out }}}
$$

The output and the input currents are given by

$$
\begin{aligned}
& I_{\text {out }}=\frac{V_{\text {out }}}{R} \\
& I_{\text {in }}=\frac{V_{\text {out }}}{(1-D)}
\end{aligned}
$$

The inductor value is calculated as

$$
L=\frac{D V_{i n}}{f \Delta i_{L}}
$$

The capacitor value is designed using:

$$
C=\frac{D V_{\text {out }}}{f R \Delta v_{c}}
$$

\subsection{The Quadratic Boost Converter}

A quadratic boost converter is configured by the components of two conventional boost converters by using single switch as shown in Figure 5.

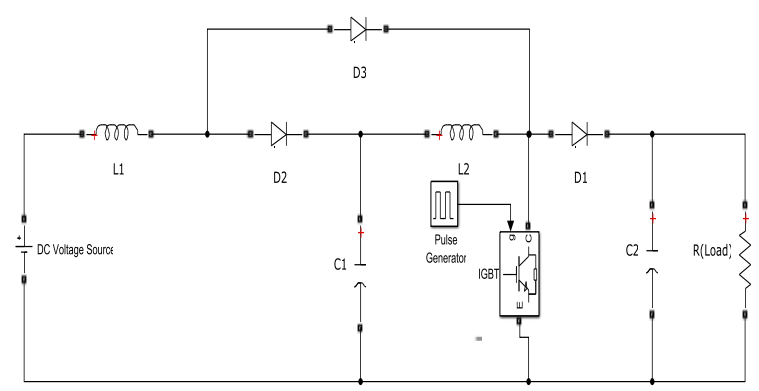

Figure 5: A quadratic boost converter

A quadratic boost converter basically comprises two capacitors, two inductors, three diodes and one switch. The boost converter has two possible modes of operation in continuous mode.

Mode 1: On-State

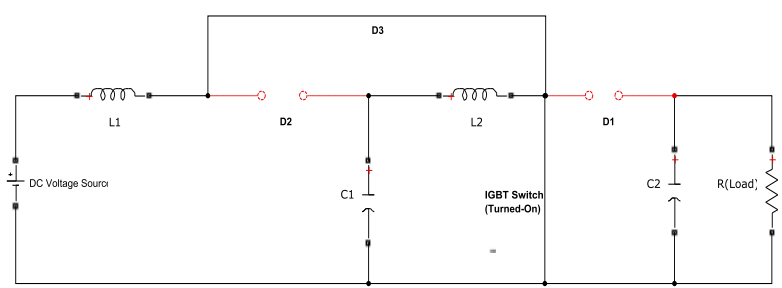

Figure 6: A quadratic boost converter (On-State)

The mode 1 circuit of quadratic boost converter is given in Figure 6. In on-state, the switch (IGBT) is turned on, D1 and D2 are reverse biased, whereas D3 is forward biased. $V_{\text {in }}$ and $\mathrm{C}_{1}$ supply currents to inductors $\mathrm{L}_{1}$ and $\mathrm{L}_{2}$ respectively. Thus, the inductor current increases in this mode.

Mode 2: Off-State

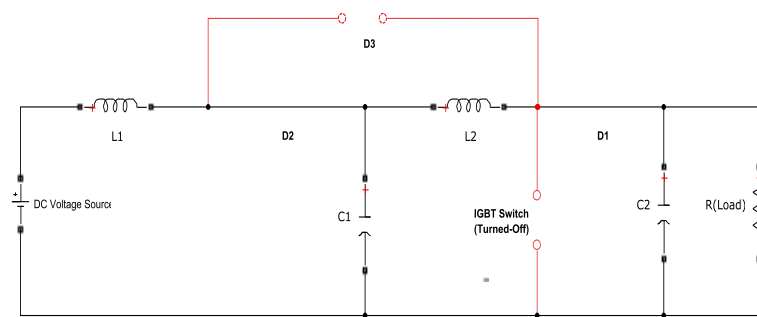

Figure 7: A quadratic boost converter (Off-State)

The mode 2 circuit of quadratic boost converter is given in Figure 7. In off-state, switch (IGBT) is turned off, D1 and D2 are forward biased, whereas D3 is reverse biased. Capacitor $\mathrm{C}_{1}$ and $\mathrm{C}_{2}$ gets charged through diode D1 and D2 from the energy stored in the inductors $\mathrm{L}_{1}$ and $\mathrm{L}_{2}$ respectively. Thus, the inductor current decreases in this mode.

Let $f$ be the switching frequency. Then,

The duty cycle is given by

$$
D=1-\frac{\sqrt{V_{\text {in }}}}{\sqrt{V_{\text {out }}}}
$$

The output and inductor currents are calculated as follows:

$$
\begin{aligned}
& I_{\text {out }}=\frac{V_{\text {out }}}{R} \\
& I_{L 1}=\frac{I_{\text {out }}}{(1-D)^{2}} \\
& I_{L 2}=\frac{I_{\text {out }}}{(1-D)}
\end{aligned}
$$

The inductors values are calculated as:

$$
\begin{aligned}
& L_{1}=\frac{D V_{i n}}{f \Delta i L_{1}} \\
& L_{2}=\frac{D V_{i n}}{f \Delta i L_{2}}
\end{aligned}
$$

The capacitors values are calculated using:

$$
C_{1,2}=\frac{D V_{i n}}{(1-D) \Delta v_{c} R f}
$$

\subsection{The Double Cascaded Boost Converter}

A double cascade boost converter is basically evolved by associating two identical elementary boosts connected in tandem, as shown in Figure 8.

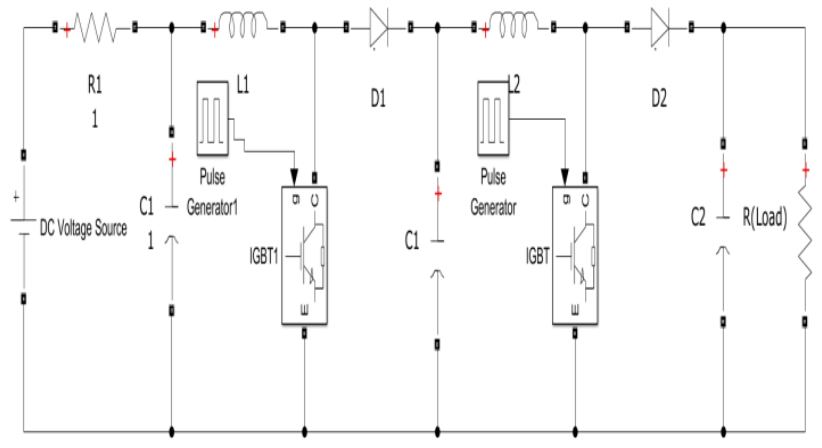

Figure 8: A double cascaded boost converter

It consists of an input voltage source Vin, two independently controlled active switches IGBT1 and IGBT2, two freewheeling diodes D1 and D2, two capacitors $\mathrm{C} 1$ and $\mathrm{C} 2$ and two inductors L1 and L2. The double cascaded boost converter has two possible modes of operation in continuous mode. 
Mode 1: On-State

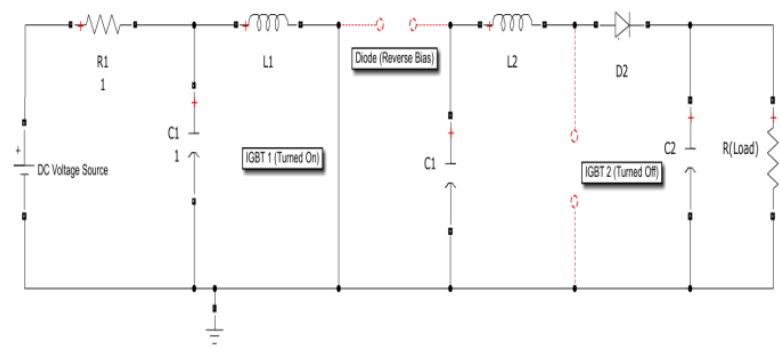

Figure 9: A double cascaded boost converter (On-State)

The mode 1 circuit of double cascaded boost converter is given in Figure 9. In on-state, the switch IGBT1 is turned on, IGBT2 will remain off, D1 is reverse biased and D2 is forward biased. The inductor L1 stores the energy.

Mode 2: Off-State

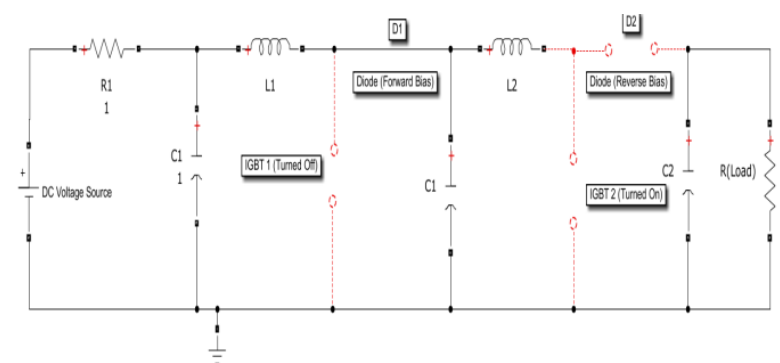

Figure 10: A double cascaded boost converter (Off-State)

The mode 2 circuit of double cascaded boost converter is given in Figure 10. In Off-state, the switch IGBT1 is turned off, IGBT2 will gets turned on, D1 becomes forward biased and $\mathrm{D} 2$ is reverse biased.

A high value capacitor Cin, act as DC-Link. Let $f$ be the switching frequency and D1 and D2. Then,

The voltage ratio is calculated as:

$$
\frac{V_{\text {in }}}{V_{\text {out }}}=\frac{1}{\left(1-D_{1}\right)\left(1-D_{2}\right)}
$$

The output and inductor currents are calculated as follows:

$$
\begin{aligned}
& I_{\text {out }}=\frac{V_{\text {out }}}{R} \\
& I_{L 2}=\frac{I_{\text {out }}}{\left(1-D_{2}\right)} \\
& I_{L 1}=\frac{I_{L 2}}{\left(1-D_{1}\right)}
\end{aligned}
$$

Where, $I_{L 2}$ is the output current of the first boost stage.

The inductors values are calculated as:

$$
\begin{aligned}
& L_{1}=\frac{D_{1} V_{i n}}{f \Delta i L_{1}} \\
& L_{2}=\frac{D_{2} V_{i n}}{f \Delta i L_{2}}
\end{aligned}
$$

The capacitors values are calculated using:

$$
\begin{aligned}
& C_{1}=\frac{D_{1} V_{1}}{\Delta v_{c 1} R f} \\
& C_{2}=\frac{D_{2} V_{\text {out }}}{\Delta v_{c 2} R f}
\end{aligned}
$$

Where, where $V_{1}$ is the output voltage for the first boost stage.

For all the above converters, the switching frequency is taken as $50 \mathrm{kHz}$, the peak-to-peak ripple voltage of the PV module is specified as $0.2 \mathrm{~V}$, and the peak-to-peak ripple of the inductor current is specified as $1 \mathrm{~A}$.

\section{MAXIMUM POWER POINT (MPP) TRACKING}

The solar PV module offers a limited output power for a given load as reflected from its I-V characteristics. In a steady state of solar irradiance and cell temperature, there is a single operating point where the output of the voltage and current results in the maximum power output.

\subsection{Perturb and Observe Technique}

The Perturb and Observe (P\&O), is the most commonly used MPPT algorithm due to its ease of implementation in its basic form. In this, the output voltage and current are sampled and output power is computed. The algorithm changes the operating voltage in the required direction and samples $d P / d V$. If $d P / d V$ is positive, then the algorithm increases in steps the voltage towards the maximum power point until $d P / d V$ is negative. This iteration is continued until the algorithm finally reaches the MPP. The voltage never actually reaches an exact value but oscillates around the maximum power point (MPP). The flowchart of the P\&O-based MPPT technique is presented in Figure 11.

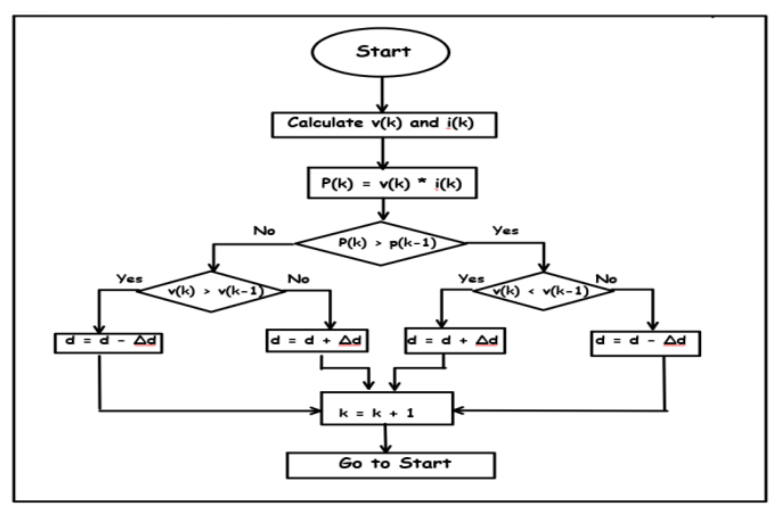

Figure 11: Flowchart of the P\&O MPPT method

Thus, the P\&O method is easy to implement but there are limitations, like oscillations around the MPP in steady state operation, slow response speed, and it may go off-track under rapidly changing atmospheric conditions.

\section{SIMULATION AND RESULTS}

The Simulink model of whole system on which analysis is done is shown below in Figure 12. It is divided into three parts the first one is PV array then the second is DC/DC converter which is drive through the MPPT technique which has been applied to extract maximum power from the PV panel and the third part is constant load. 


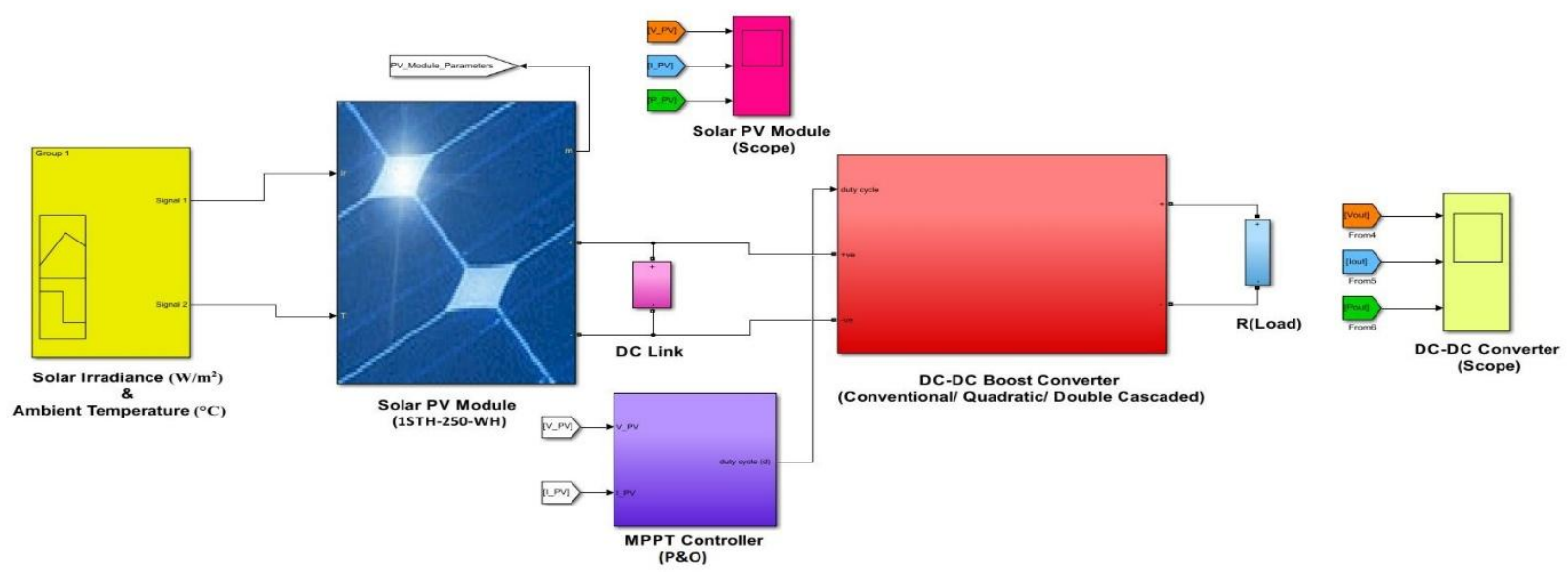

Figure 12: Simulink Model of Solar PV Module connected Boost Converters with MPPT controller

\subsection{PV Module - 1STH-250-WH}

The simulation model consists of PV array with a peak power of 2000 Watt. The PV array consists of strings of PV modules connected in parallel, NP. Each string consists of modules connected in series, NS. The PV array consists of 08 parallel strings and 01 series-connected modules per string. The inputs to the PV array are sun irradiance $\left(\mathrm{W} / \mathrm{m}^{2}\right)$ and cell temperature $\left({ }^{\circ} \mathrm{C}\right)$. The main characteristic of the preset PV module used (1Soltech 1STH-250-WH) is given in Table 1.

Table 1: Characteristics of 1Soltech 1STH-250-WH

\begin{tabular}{|c|c|}
\hline Specifications & Values \\
\hline Maximum power (Pmax) & $2000-$ Watt \\
\hline Cells per module & 60 \\
\hline Open-circuit voltage (VOC) & 37.3 Volt \\
\hline Short-circuit current (Isc) 5 & $8.66 \mathrm{Amp}$ \\
\hline Voltage at maximum power point (VMPP) & 30.7 Volt \\
\hline Current at maximum power point (IMPP) & $8.15 \mathrm{Amp}$ \\
\hline
\end{tabular}

The $\mathrm{I}-\mathrm{V}$ and $\mathrm{P}-\mathrm{V}$ characteristics of the $\mathrm{PV}$ array are shown in Figure 13.

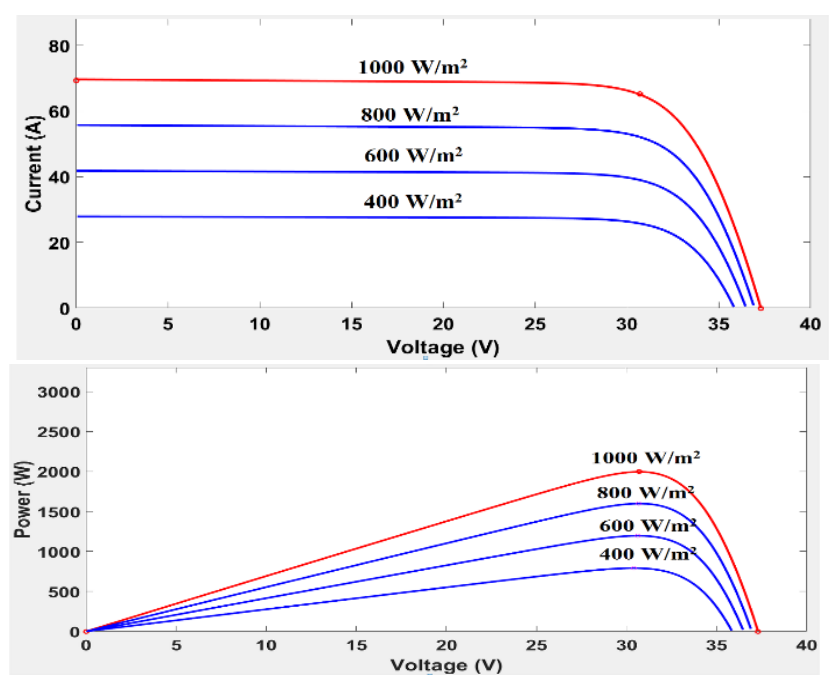

Figure 13: PV characteristics of array for different combinations of solar irradiance and temperature.
Simulation and analysis are done for different combinations values of solar irradiance and temperature. Signal Builder Input for Solar Irradiance values: $400 \mathrm{~W} / \mathrm{m}^{2}, 600 \mathrm{~W} / \mathrm{m}^{2}, 800$ $\mathrm{W} / \mathrm{m}^{2}$ and $1000 \mathrm{~W} / \mathrm{m}^{2}$ at ambient temperature $25^{\circ} \mathrm{C}$ and for Solar irradiance $1000 \mathrm{~W} / \mathrm{m}^{2}$ at ambient temperature of $25^{\circ} \mathrm{C}$, $35^{\circ} \mathrm{C}$ and $45^{\circ} \mathrm{C}$. The plot is shown in Figure 14 and 15 , respectively.

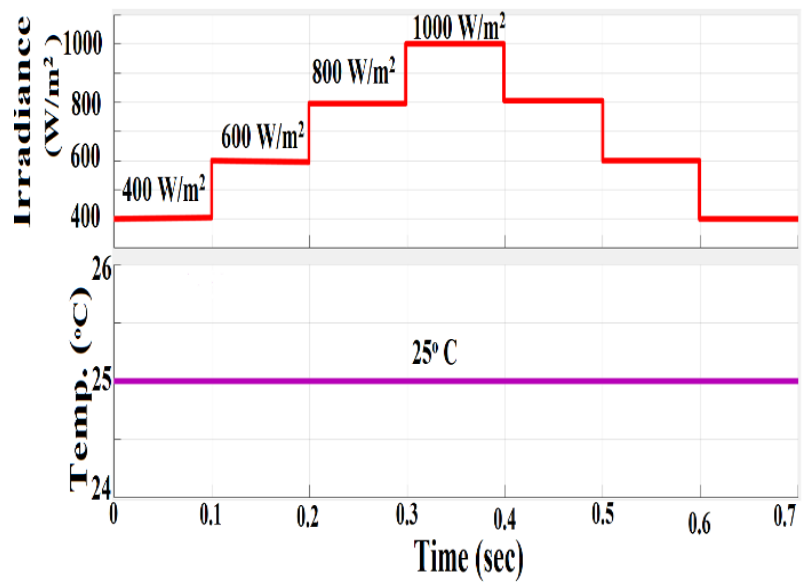

Figure 14: Signal Builder Input for Solar Irradiance: 400 $\mathrm{W} / \mathrm{m}^{2}, 600 \mathrm{~W} / \mathrm{m}^{2}, 800 \mathrm{~W} / \mathrm{m}^{2}$ and $1000 \mathrm{~W} / \mathrm{m}^{2} @$ ambient temperature $25^{\circ} \mathrm{C}$.

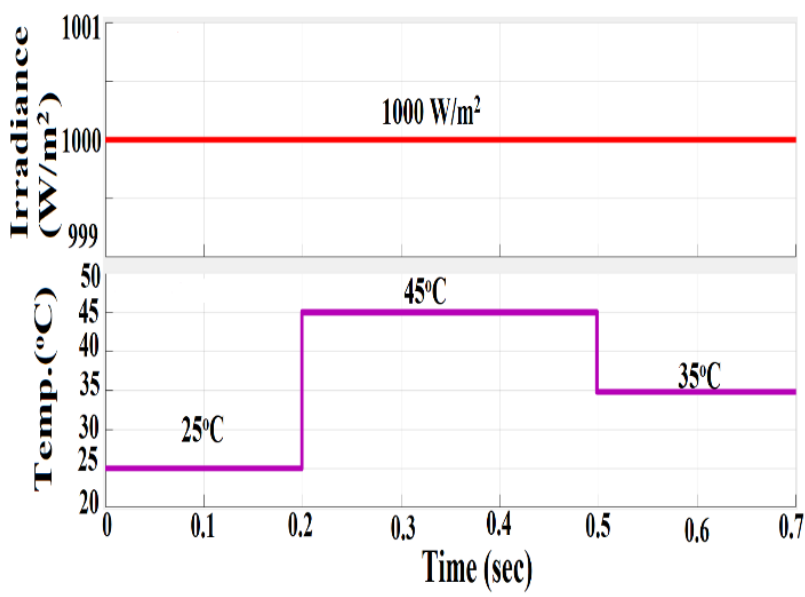

Figure 15: Signal Builder Input for Solar Irradiance 1000 $\mathrm{W} / \mathrm{m}^{2}$ at ambient temperature of $25^{\circ} \mathrm{C}, 35^{\circ} \mathrm{C}$ and $45^{\circ} \mathrm{C}$. 


\subsection{Solar PV System with Conventional Boost Converter}

The waveforms of output voltage, current and power of Solar PV system connected to conventional boost converter with P\&O MPPT Controller at standard ambient condition 1000 $\mathrm{W} / \mathrm{m}^{2}, 25^{\circ} \mathrm{C}$ is shown in Figure 16 and for different combinations of solar irradiance and temperature. is shown in Figure 17 and 18 .

At $1000 \mathrm{~W} / \mathrm{m}^{2}, 25^{\circ} \mathrm{C}$

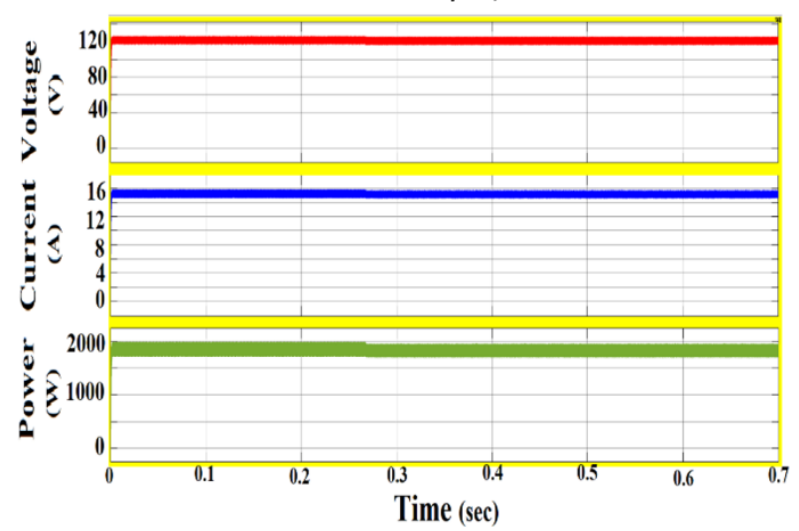

Figure 16: CBC Output waveforms at standard conditions.

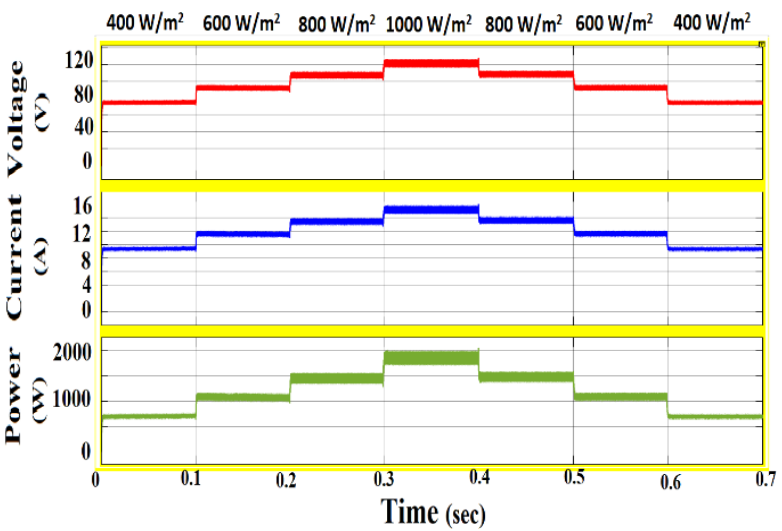

Figure 17: $\mathrm{CBC}$ Output waveforms at temperature = $\mathbf{2 5}^{\circ} \mathrm{C} @$ different Irradiation.

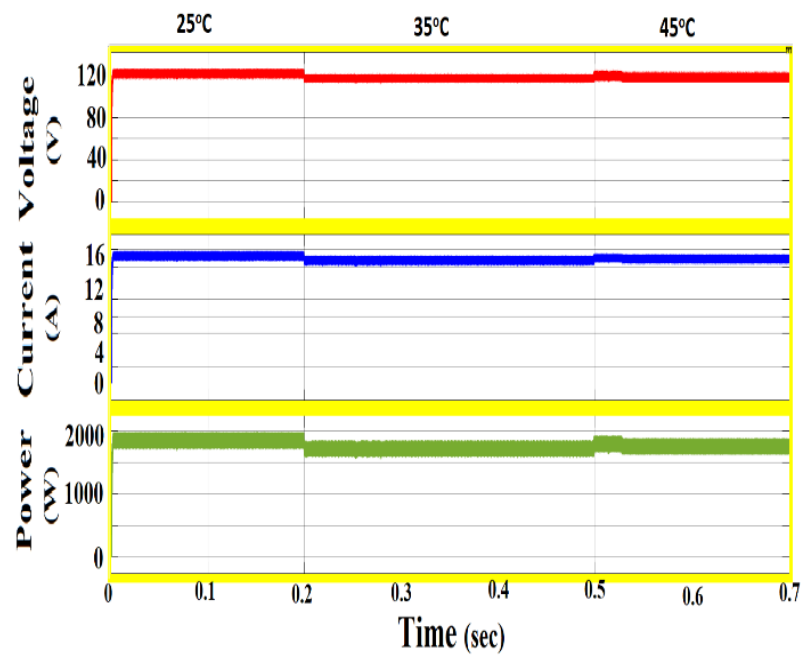

Figure 18: $\mathrm{CBC}$ Output waveforms at irradiation $=1000$ W/m²@ different temperatures.
The results have been summarized in Table 2 .

Table 2. Performance analysis of Solar PV system Connected CBC with P\&O based MPPT Controller

\begin{tabular}{|c|c|c|c|}
\hline $\begin{array}{c}\text { Irradiance/ } \\
\text { Temp } \\
\left(\mathbf{w} / \mathbf{m}^{\mathbf{2}} \mathbf{~}^{\mathbf{0}} \mathbf{C}\right)\end{array}$ & $\begin{array}{c}\text { Max. Power } \\
\text { of PV } \\
\text { Module } \\
\mathbf{P}_{\text {MPP }}(\mathbf{w})\end{array}$ & $\begin{array}{c}\text { Solar PV } \\
\text { Module } \\
\text { Terminal } \\
\text { Voltage } \\
\mathbf{P}_{\mathbf{P V}}(\mathbf{w})\end{array}$ & $\begin{array}{c}\text { MPPT } \\
\text { Efficiency } \\
\boldsymbol{\eta}_{\text {MPPT }}\end{array}$ \\
\hline 400,25 & 792 & 786 & $90.60 \%$ \\
\hline 600,25 & 1197 & 1109 & $92.68 \%$ \\
\hline 800,25 & 1599 & 1521 & $95.15 \%$ \\
\hline 1000,25 & 2000 & 1893 & $94.65 \%$ \\
\hline 1000,35 & 1914 & 1464 & $76.51 \%$ \\
\hline 1000,45 & 1830 & 1392 & $76.84 \%$ \\
\hline
\end{tabular}

\subsection{Solar PV System with Quadratic Boost Converter}

The waveforms of output voltage, current and power of Solar PV Module connected to quadratic boost converter at standard ambient condition $1000 \mathrm{~W} / \mathrm{m}^{2}, 25^{\circ} \mathrm{C}$ is shown in Figure 19 and for different combinations of solar irradiance and temperature. is shown in Figure 20 and 21.

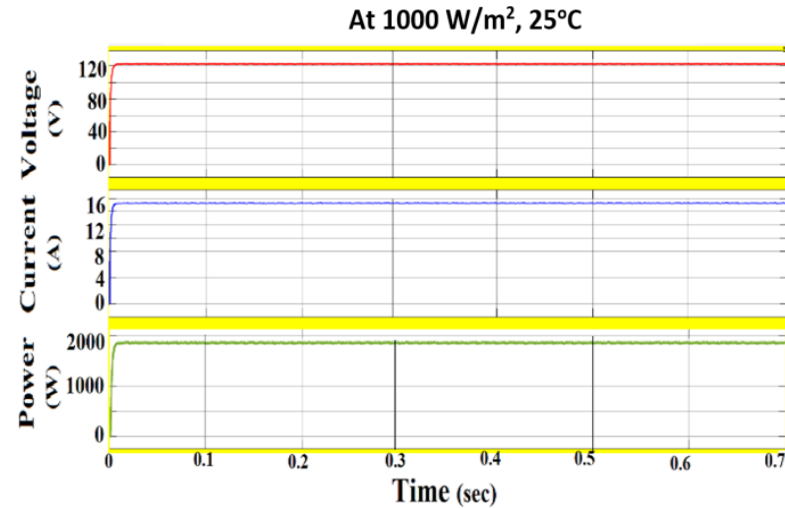

Figure 19: QBC Output waveforms at standard conditions.

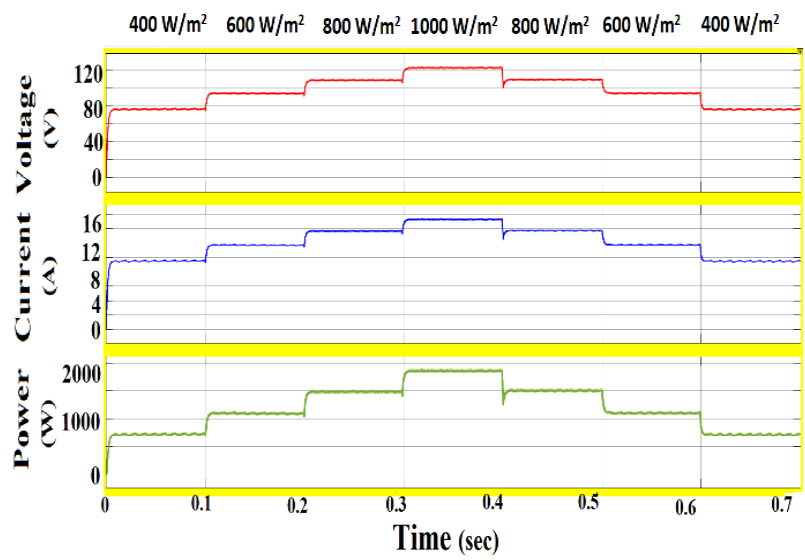

Figure 20: QBC Output waveforms at temperature = $25^{\circ} \mathrm{C} @$ different Irradiation. 


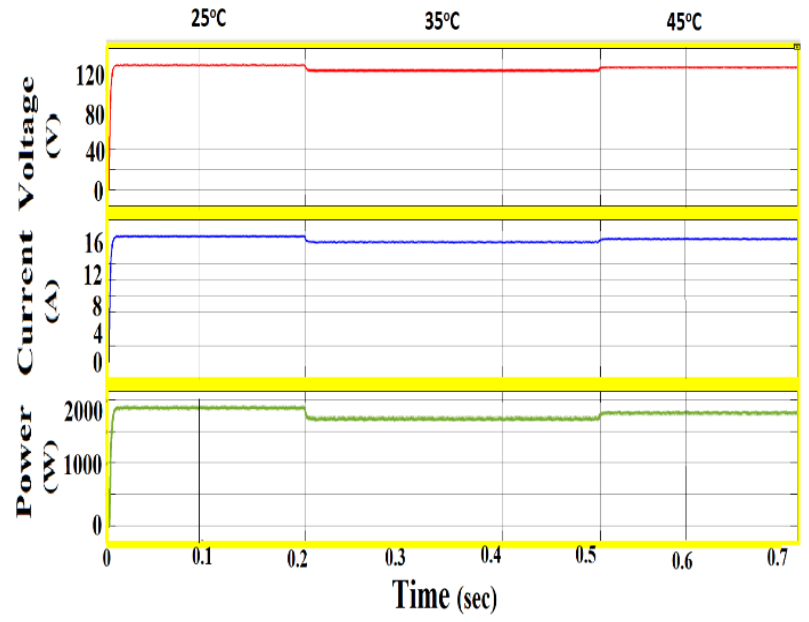

Figure 21: $Q B C$ Output waveforms at irradiation $=1000$ W/m²@ different temperatures.

The results have been summarized in Table 3 .

Table 3. Performance analysis of Solar PV Connected QBC with P\&O based MPPT Controller

\begin{tabular}{|c|c|c|c|}
\hline $\begin{array}{c}\text { Irradiance/ } \\
\text { Temp } \\
\left(\mathbf{w} / \mathbf{m}^{\mathbf{2}},{ }^{\mathbf{0}} \mathbf{C}\right)\end{array}$ & $\begin{array}{c}\text { Max. } \\
\text { Power of } \\
\text { PV } \\
\text { Module } \\
\mathbf{P}_{\text {MPP }}(\mathbf{w})\end{array}$ & $\begin{array}{c}\text { Solar PV } \\
\text { Module } \\
\text { Terminal } \\
\text { Voltage } \\
\mathbf{P}_{\mathbf{P V}}(\mathbf{w})\end{array}$ & $\begin{array}{c}\text { MPPT } \\
\text { Efficiency } \\
\boldsymbol{\eta}_{\text {MPPT }}(\boldsymbol{\%})\end{array}$ \\
\hline 400,25 & 792 & 761 & $96.14 \%$ \\
\hline 600,25 & 1197 & 1173 & $97.97 \%$ \\
\hline 800,25 & 1599 & 1581 & $98.86 \%$ \\
\hline 1000,25 & 2000 & 1982 & $98.68 \%$ \\
\hline 1000,35 & 1914 & 1893 & $98.88 \%$ \\
\hline 1000,45 & 1830 & 1823 & $98.46 \%$ \\
\hline
\end{tabular}

\subsection{Solar PV System with Double Cascaded Boost Converter}

The waveforms of output voltage, current and power of Solar PV Module connected to double cascaded boost converter at standard ambient condition $1000 \mathrm{~W} / \mathrm{m}^{2}, 25^{\circ} \mathrm{C}$ is shown in Figure 22 and for different combinations of solar irradiance and temperature. is shown in Figure 23 and 24.

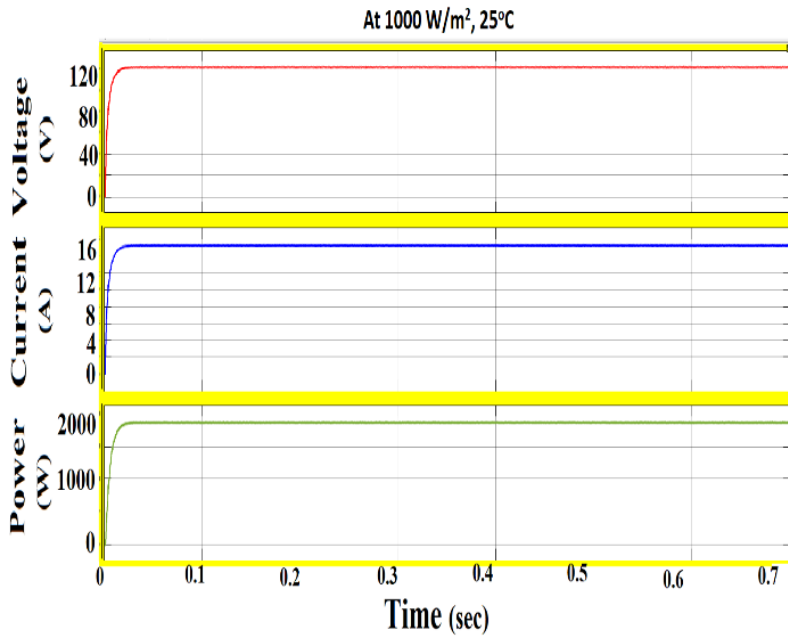

Figure 22: DCBC Output waveforms at standard conditions.

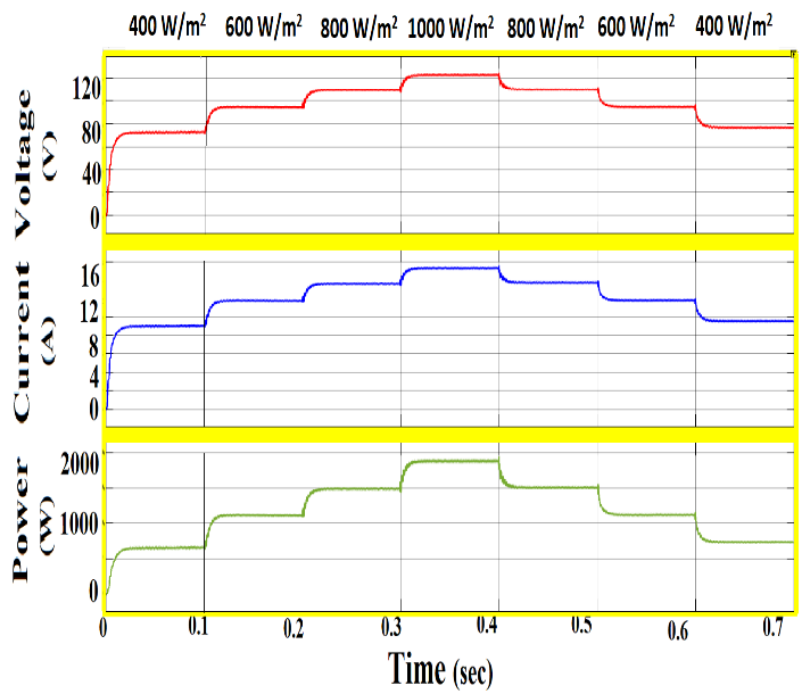

Figure 23: DCBC Output waveforms at temperature = $\mathbf{2 5}^{\circ} \mathrm{C}$ @ different irradiation.

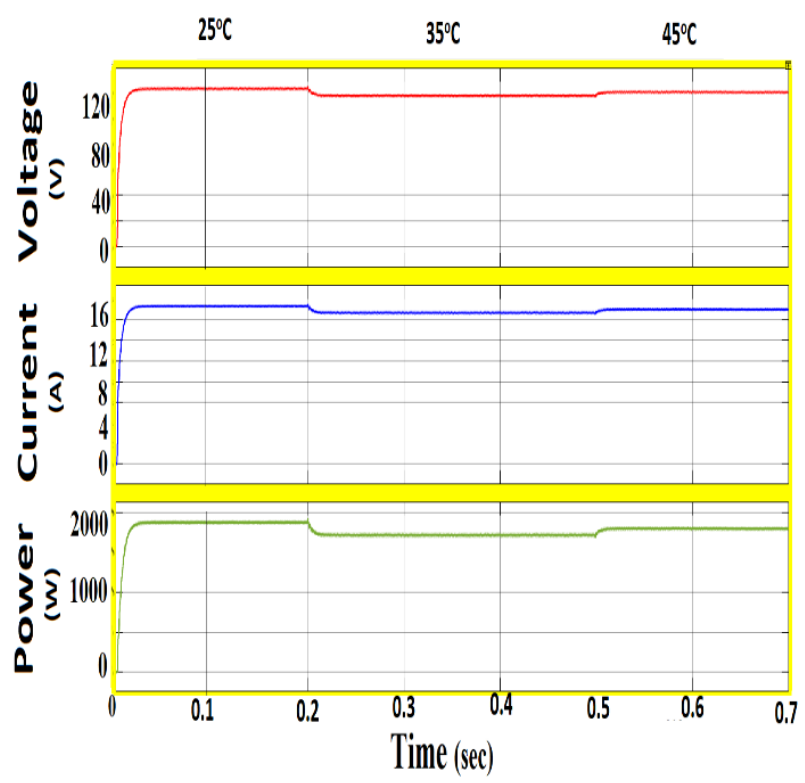

Figure 24: DCBC Output waveforms at irradiation = 1000 W/m2 @ different temperature. 
The results have been summarized in Table 4

Table 4. Performance analysis of Solar PV Connected DCBC with P\&O based MPPT Controller

\begin{tabular}{|c|c|c|c|}
\hline $\begin{array}{c}\text { Irradiance/ } \\
\text { Temp } \\
\left(\mathbf{w} / \mathbf{m}^{\mathbf{2}} \mathbf{~}^{\mathbf{0}} \mathbf{C}\right)\end{array}$ & $\begin{array}{c}\text { Max. } \\
\text { Power of } \\
\mathbf{P V} \\
\text { Module } \\
\mathbf{P}_{\text {MPP }}(\mathbf{w})\end{array}$ & $\begin{array}{c}\text { Solar PV } \\
\text { Module } \\
\text { Terminal } \\
\text { Voltage } \\
\mathbf{P}_{\mathbf{P V}}(\mathbf{w})\end{array}$ & $\begin{array}{c}\text { MPPT } \\
\text { Efficienc } \\
\mathbf{y} \\
\boldsymbol{\eta}_{\text {MPPT }}\end{array}$ \\
\hline 400,25 & 792 & 750 & $94.70 \%$ \\
\hline 600,25 & 1197 & 1156 & $96.57 \%$ \\
\hline 800,25 & 1599 & 1562 & $97.69 \%$ \\
\hline 1000,25 & 2000 & 1971 & $98.54 \%$ \\
\hline 1000,35 & 1914 & 1887 & $98.58 \%$ \\
\hline 1000,45 & 1830 & 1799 & $98.29 \%$ \\
\hline
\end{tabular}

\section{CONCLUSIONS}

In this study for the given solar PV energy system, it is observed that, under standard ambient condition (i.e. 1000 $\left.\mathrm{w} / \mathrm{m}^{2}, 25^{\circ} \mathrm{C}\right)$, the MPPT efficiency obtained for conventional, quadratic and double cascaded boost converters are $94.65 \%$, $98.68 \%$ and $98.54 \%$ respectively. Thus, it is concluded that for same voltage conversion ratio, cascaded converters exhibit better efficiency in comparison to a CBC. The efficiency analysis reveals that the DCBC has an imperceptible difference with that of QBC. In case of $\mathrm{CBC}$ when the system approaches the MPP, the perturbing nature of the P\&O MPPT algorithms involves oscillations across the MPP, whereas it is greatly reduced for cascaded converters. Among all, the QBC shows the fastest tracking speed and a relatively less settling time and is simple in configuration, as it is realized by assembling the components of two boost converters by using single switch. Therefore, all in all quadratic boost converter is the best topology for the given solar PV system.

\section{REFERENCES}

[1] K. Dubey and M. T. Shah, "Design and simulation of Solar PV system," 2016 International Conference on Automatic Control and Dynamic Optimization Techniques (ICACDOT), Pune, 2016, pp. 568-573, doi: 10.1109/ICACDOT.2016.7877649.

[2] V. Balacoumarane, B. Karthik, K. V. S. Pranav, S. A. Sandeep and S. Thampatty, "Design and implementation of PV system for a constant voltage operation," 2017 International Conference On Smart Technologies For Smart Nation (SmartTechCon), Bangalore, 2017, pp. 1269-1273, doi: 10.1109/SmartTechCon.2017.8358570.

[3] X. Zhou, M. Liu, Y. Ma and Z. Gao, "An Overview of Photovoltaic System," 2018 Chinese Control and Decision Conference (CCDC), Shenyang, 2018, pp. 4949-4954, doi: 10.1109/CCDC.2018.8407988.

[4] W. Ali, H. Farooq, A. U. Rehman, Q. Awais, M. Jamil and A. Noman, "Design Considerations of Stand-Alone Solar Photovoltaic Systems," 2018 International Conference on Computing, Electronic and Electrical Engineering (ICE Cube), Quetta, 2018, pp. 1-6, doi: 10.1109/ICECUBE.2018.8610970.
[5] A. N. Mizard, D. R. Aryani, A. Verdianto and C. Hudaya, "Design and Implementation Study of $3.12 \mathrm{kWp}$ On - Grid Rooftop Solar PV System," 2019 International Conference on Electrical Engineering and Informatics (ICEEI), Bandung, Indonesia, 2019, pp. 465-470, doi: 10.1109/ICEEI47359.2019.8988862.

[6] Y. Ajgaonkar, M. Bhirud and P. Rao, "Design of Standalone Solar PV System Using MPPT Controller and Self-Cleaning Dual Axis Tracker," 2019 5th International Conference on Advanced Computing \& Communication Systems (ICACCS), Coimbatore, India, 2019, pp. 27-32, doi: 10.1109/ICACCS.2019.8728494.

[7] Lee, S.W., Do, H.L.: 'High step-up coupled-inductor cascade boost DC-DC converter with lossless passive snubber', IEEE Trans. Ind. Electron., 2018, 65, (10), pp. 7753-7761

[8] Q. Pan, H. Liu, P. Wheeler and F. Wu, "High step-up cascaded DC-DC converter integrating coupled inductor and passive snubber," in IET Power Electronics, vol. 12, no. 9, pp. 2414-2423, 78 2019, doi: 10.1049/ietpel.2018.5706.

[9] A. Ajami, H. Ardi and A. Farakhor, "A Novel High Stepup DC/DC Converter Based on Integrating Coupled Inductor and Switched-Capacitor Techniques for Renewable Energy Applications," in IEEE Transactions on Power Electronics, vol. 30, no. 8, pp. 4255-4263, Aug. 2015, doi: 10.1109/TPEL.2014.2360495.

[10] A. Naderi and K. Abbaszadeh, "High step-up DC-DC converter with input current ripple cancellation," in IET Power Electronics, vol. 9, no. 12, pp. 2394-2403, 510 2016, doi: 10.1049/iet-pel.2015.0723. Brown, L. D., Hua, H., and Gao, C. 2003. A widget framework for augmented interaction in SCAPE

[11] Selva Kumar. R, Gayathri Deivanayaki. V. P, Vignesh. C. J, Naveena. P, "Design and Comparison of Quadratic Boost Converter with Boost Converter", IJERT Vol. 5 Issue 01, January-2016.

[12] N. Boujelben, F. Masmoudi, M. Djemel and N. Derbel, "Design and comparison of quadratic boost and double cascade boost converters with boost converter," 2017 14th International Multi-Conference on Systems, Signals \& Devices (SSD), Marrakech, 2017, pp. 245-252, doi: 10.1109/SSD.2017.8167022.

[13] Trishan Esram, Patrick L. Chapman, "Comparison of Photovoltaic Array Maximum Power Point Tracking Techniques", IEEE Transactions on Energy Conversion, Vol. 22, No. 2, June 2007.

[14] Bidyadhar Subudhi, Raseswari Pradhan, "A Comparative Study on Maximum Power Point Tracking Techniques for Photovoltaic Power Systems", IEEE Transactions on Sustainable Energy, vol. 4, no. 1, January 2013.

[15] A. K. Gupta and R. Saxena, "Review on widely-used MPPT techniques for PV applications," 2016 International Conference on Innovation and Challenges in Cyber Security (ICICCS-INBUSH), Noida, 2016, pp. 270-273, doi: 10.1109/ICICCS.2016.7542321.

[16] Ali M. Eltamaly, Almoataz Y. Abdelaziz, "Modern Maximum Power Point Tracking Techniques for Photovoltaic Energy Systems" ISBN 978-3-030-05578-3 (eBook) () Springer Nature Switzerland AG 2020. 